\title{
Assessment of health related quality of life of drug resistant tuberculosis patients
}

\author{
Sonia Dhiman', Rekha Bansal ${ }^{2}$, Dinesh Kansal ${ }^{3, *}$, Parveen K. Sharma ${ }^{4}$ \\ ${ }^{1}$ Junior Resident, ${ }^{2}$ Associate Professor, ${ }^{3,4}$ Professor \& HOD, ${ }^{1,3,4}$ Dept. of Pharmacology, ${ }^{2}$ Dept. of Pulmonary Medicine, ${ }^{1,2,3}$ Dr. \\ Rajendra Prasad Government Medical College Kangra, Tanda, Himachal Pradesh, ${ }^{4}$ Shri Lal Bahadur Shastri Government \\ Medical College \& Hospital Mandi, Himachal Pradesh, India
}

${ }^{*}$ Corresponding Author

Email: dinesh.kansal56@gmail.com

\begin{abstract}
Objectives: Assessment of Health Related Quality of Life (HRQoL) of drug resistant tuberculosis patients at the start of treatment under PMDT regime.

Materials and Methods: This observational study was conducted on a cohort of 172 drug resistant tuberculosis (DR-TB) patients at the time of registration under PMDT regime. Patients who started their treatment between January 2016 and December 2016 were included in the study after approval from IEC. A validated WHOQOL-BREF questionnaire was used for interviewing the patients. This questionnaire assesses HRQoL on 0-100 transforming scale in four domains - Physical, Psychological, Social relationship and Environmental.
\end{abstract}

Results: Out of 172 participants, $50(29.1 \%)$ were females and $122(70.9 \%)$ were males. Their mean age \pm SD was $40.23 \pm 15.77$ years. $77.9 \%$ participants were married. $97.7 \%$ of them were residing in rural areas. Most of the participants were from district Mandi (33.1\%) and Kangra (20.9\%). Scores of Physical domain were 39.76 \pm 13.88 ; Psychological domain were 37.23 \pm 14.89 ; Social relationship domain were $43.28 \pm 13.48$ and Environment domain were 50.66 \pm 9.13 . Overall HRQoL scores were $42.73 \pm 10.11$.

Conclusion: Chronic diseases like tuberculosis affect all domains of HRQoL and there is need to consider HRQoL domains of patients of DR-TB along with smear positivity and mortality to evaluate the success of any national heath programme.

Keywords: Drug resistant tuberculosis, Health related quality of life, WHO-QOL BREF.

\section{Introduction}

World Health Organization (WHO) defines 'Quality of Life' (QOL) as individual's perception of their position in life in the context of the culture and value systems in which they live and in relation to their goals, expectations, standards and concerns. ${ }^{1}$ When quality of life is considered in the context of health and disease, it is commonly referred to as 'health related quality of life' (HRQoL) to differentiate it from other aspects of quality of life. HRQoL is multidimensional and incorporates domains related to physical, mental, emotional and social well being. ${ }^{2}$ TB is a major health problem. It causes ill health among millions of people each year and ranks alongside Human Immunodeficiency Virus (HIV) as a leading cause of death worldwide. ${ }^{3}$ With the emergence of resistance to drugs, TB has become a significant public health problem and an obstacle to effective TB control. TB control has been given a high priority in the health sector. Revised National Tuberculosis Programme (RNTCP) has introduced the Programmed Management of Drug Resistant Tuberculosis (PMDT) services since 2007 to address the needs of DR-TB patients. ${ }^{4}$ TB in India carries a social stigma due to perceived consequences of cross infection. The resultant social rejection and isolation leads to long term impairment of patient's psychological well being. Many DR-TB patients also report experience of negative emotions, such as anxiety and fear. They are at even higher risk of psychological, social, and economic difficulties due to delay in the diagnosis of DR-TB. Further, patients had already taken CAT-I and CAT-II drugs and suffered from their side effects. This may lead to decreased compliance and follow ups resulting in poor clinical outcomes, relapses and increased mortality rates. Therefore, for a comprehensive assessment of patient health status, it is essential to consider the overall impact of TB on health and patient's perception of well being besides routine clinical, radiological and bacteriological assessment. This can be performed by measuring the HRQoL, that has several dimensions. Physical health is related to level of independence, activities of daily living, pain and discomfort, dependence on medicinal substances, lack of energy, sleep and rest, mobility and capacity to work. Psychological health depends upon self esteem, positive and negative feelings, bodily appearance and spirituality while social relationship depends upon social support, personal relationship and sexuality. On the other hand environmental health comprises of financial resources, physical safety and security, quality of home environment, quality and accessibility to health and social care, transport and opportunities for leisure activities. $^{5}$ The goal and purpose of HRQoL measurement is to quantify the degree to which the medical condition or its treatment impact the individual's life in a valid and reproducible way. In general, the programmed data in India focus on outcomes such as mortality and bacteriological markers of response but do not consider any other dimensions of 
health. There has been little effort to consider patient's HRQoL in national health programmes. The success of any health care programme depends on the medical and paramedical personnel. In case of PMDT, where success depends on the supervised therapy by workers, it is important to sensitize them to look beyond disease, disability and symptoms. It is required to incorporate the measurement of HRQoL of TB patients to have an in depth understanding of the effect of disease on various dimensions of health. Thus the current study was planned to assess the HRQoL of the DR-TB patients at start of treatment.

\section{Materials and Methods}

The present study was an observational questionnaire based study on a cohort of DR-TB patients that was conducted in the Department of Pulmonary Medicine and Department of Pharmacology, Dr. RPGMC Kangra at Tanda, Himachal Pradesh, after approval from Institutional Ethics Committee wide letter no. ECR/490/Inst/HP/2013. Total duration of study was one year from January 2016 to December 2016.

\section{Inclusion criteria}

Patients who were diagnosed of DR-TB through CBNAAT and Culture and Sensitivity Test and were registered under PMDT regime during January 2016 to December 2016.

\section{Exclusion criteria}

1. Patients not willing to participate in the study.

2. Patients below 18 years of age as they were treated in the Department of Pediatrics.

\section{Questionnaire}

Patients were explained the purpose of study and written informed consent was taken. Information regarding their age, sex, marital status, residence, education and occupation was taken.

A validated 26 item scale, WHOQOL-BREF questionnaire was used for interviewing the patients. The questionnaire has four domains i.e. physical health, psychological health, social relationship and environment. It has been validated and translated in various languages including Hindi. ${ }^{6}$

\section{Statistical analysis}

Data was entered in MS excel and analyzed using SPSS version 21 software. Domain scores were scaled in a positive direction (i.e. higher scores denotes higher quality of life) except three questions in which scores were reversed. The mean score of items within each domain was used to calculate the domain raw score. The raw scores were then converted into transformed score as per WHOQOL-BREF quality of life assessment tool. ${ }^{7}$ The overall HRQoL score was the average of the mean scores of the domains.

The quantitative data was analysed and expressed as mean $\pm \mathrm{SD}$ and percentages.

\section{Results}

Out of 172 participants, 158 (91.9\%) were of acquired MDR-TB, 9 (5.2\%) were of primary MDR-TB and $5(2.9 \%)$ were of extensive DR-TB (XDR-TB) as diagnosed by CBNAAT and Culture and Sensitivity Test. The mean age \pm SD was $40.23 \pm 15.77$ years. Maximum participants were from district Mandi (33.1\%) followed by district Kangra (20.9\%). According to Body Mass Index, 118 (68.6\%) were underweight, $50(29.1 \%)$ were of normal weight, 3 $(1.7 \%)$ were overweight and $1(0.6 \%)$ participant was obese.

Table 1: Socio-demographic profile of study participants $(n=172)$

\begin{tabular}{|l|c|c|c|}
\hline \multicolumn{1}{|c|}{ Factors } & Variables & $\begin{array}{c}\text { Number of } \\
\text { participants }\end{array}$ & Percentage \\
\hline Sex & Male & 122 & $70.9 \%$ \\
\hline & Female & 50 & $29.1 \%$ \\
\hline Age & $18-35$ years & 76 & $44.2 \%$ \\
\hline & $36-53$ years & 62 & $36.0 \%$ \\
\hline & $54-71$ years & 29 & $16.9 \%$ \\
\hline & $>71$ years & 5 & $2.9 \%$ \\
\hline Marital status & Married & 134 & $77.9 \%$ \\
\hline & Unmarried & 38 & $22.1 \%$ \\
\hline $\begin{array}{l}\text { Residential } \\
\text { status }\end{array}$ & Rural & 168 & $97.7 \%$ \\
\hline & Urban & 4 & $2.3 \%$ \\
\hline
\end{tabular}




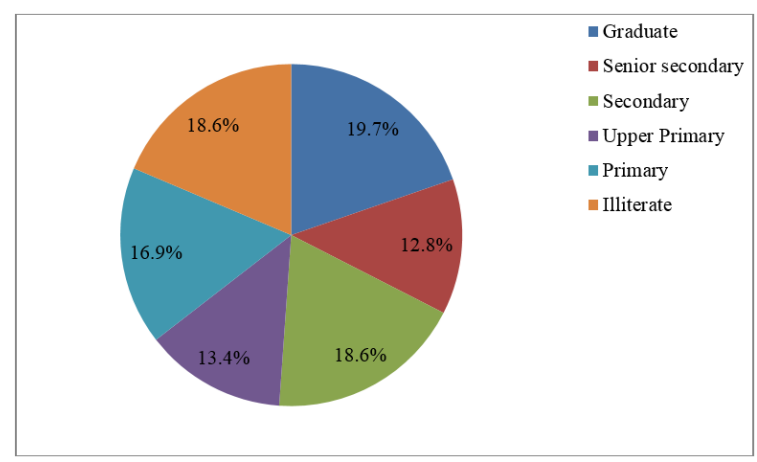

Fig. 1: Educational status of study population $(n=172)$

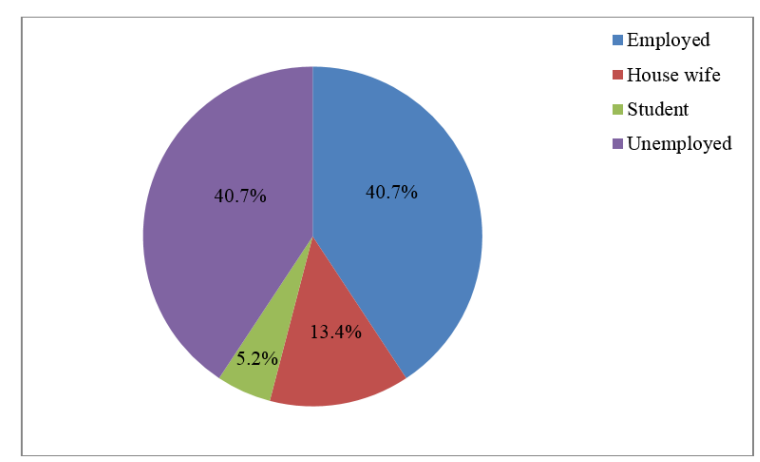

Fig. 2: Occupational status of study population $(n=172)$

General Health: The mean \pm SD HRQoL score of two global WHOQol-BREF questions - 'overall rating of quality of life' and 'overall satisfaction with health' was $4.52 \pm 1.18$.

Domain scores: HRQoL scores of psychological domain (37.23 \pm 14.89$)$ were lowest as shown in Table 2 and Figure 3. Overall HRQoL scores were only 42.73 \pm 10.11 .

Table 2: HRQoL mean domain scores $(n=172)$

\begin{tabular}{|l|c|}
\hline \multicolumn{1}{|c|}{ Domains } & $\begin{array}{l}\text { Scores } \\
(\text { Mean } \pm \text { SD) }\end{array}$ \\
\hline Physical health & $39.76 \pm 13.88$ \\
\hline Psychological & $37.23 \pm 14.89$ \\
\hline Social relationship & $43.28 \pm 13.48$ \\
\hline Environment & $50.66 \pm 9.13$ \\
\hline Overall HRQoL & $42.73 \pm 10.11$ \\
\hline
\end{tabular}

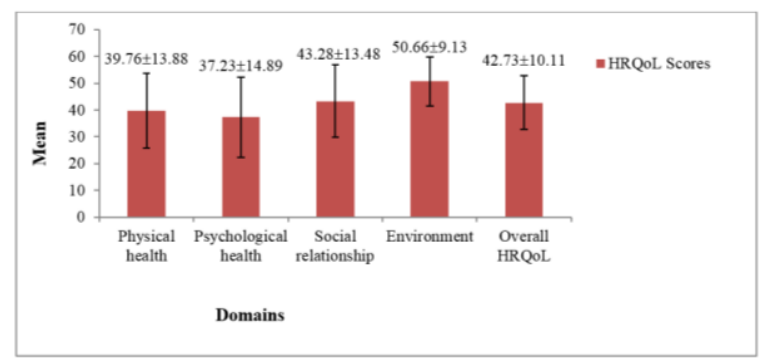

Fig. 3: HRQoL mean domain scores $(n=172)$

\section{Discussion}

The present study was an observational study conducted to assess the perception of DR-TB patients about their HRQoL at the start of treatment. The present study revealed that $94.8 \%$ of participants were of acquired MDR-TB and only $5.2 \%$ were of primary MDR-TB. Acquired MDR-TB participants had already taken CAT-I and CAT-II drugs, so their HRQoL was affected more. Majority of participants were in the age group of 18-53 years, thereby affecting their productivity and earnings. Similar age groups were affected by DR-TB in previous studies. ${ }^{8-11} 78 \%$ participants were married. Similar finding was seen in other studies. $^{8-10}$ DR-TB interfered with sexual relationship of married couples as they lost interest in sex due to their illness and weakness. So social relationship domain was affected in large number of participants. About $41 \%$ were rendered unemployed due to ill health and need to visit health institution regularly during intensive phase of six months. It further affected social interaction leading to depression.

$68.6 \%$ of participants were underweight due to which they might not be satisfied with their bodily appearance affecting the psychological domain. The general health scores were very low. This indicates that participants had difficulty in carrying out their daily life activities due to illness and perceived their overall health as poor due to the fear of further deterioration. Similar findings were observed in other studies also. ${ }^{11,12}$ The mean HRQoL scores of all the domains were low which showed that TB had negative effect on HRQoL of the participants. This finding was in coherence with various other studies conducted in different areas. ${ }^{5,8-}$ 11,13-15 Among all the domains, the psychological and physical health domains were worst affected as compared to other domains. This finding was similar to previous studies..$^{10,13,14,16}$ The physical health was affected due to longer period of medication, painful injections and adverse effects of drugs. The psychological health was affected more than physical health because participants experienced more psychological distress and emotional problems than physical problems. Same finding was seen in a study by Muhammad et al. ${ }^{12}$

\section{Limitations}

No data for WHOQOL BREF are available for healthy Indian adults. A control group could have been used for comparison, to know the extent of HRQoL impairment of DR-TB patients. Despite these limitations, it would still seem reasonable to assume that overall conclusions are valid.

\section{Conclusion}

On the start of treatment, HRQoL parameters of the patients of DR-TB were impaired by the disease. Worst affected were the psychological and physical domains. It is suggested that HRQoL of the DR-TB patients 
should be assessed at various stages of treatment. This would help in evaluation of efficacy of treatment and effectiveness of the programme.

\section{Financial Disclosure and conflict of interest}

There was no financial burden on the participants because of participation in the study. There was no conflict of interest of investigators.

\section{Acknowledgement}

Financial support was provided to this project by the Indian Council of Medical Research under shortstudentship scheme.

\section{References}

1. Skevington SM, Lotfy M, O'Connell KA. The World Health Organization's WHOQOL-BREF quality of life assessment: Psychometric properties and results of the international field trial. A Report from the WHOQOL Group. Qual Life Res 2004;13:299-310.

2. Foundation Health Measure Report. Health-Related Quality of Life and Well Being 2010. Available from: http://www.healthypeople.gov/sites /default/files/ HRQoLWBFullReport.pdf (Accessed on 14 December 2017).

3. World Health Organization. Global Tuberculosis Report 2015. Available from: www.who.int/tb/publications/global_report/ (Accessed on 14 December, 2017).

4. Dixit AK, Chaudhary E, Dixit J. Programmatic Management of Drug Resistant Tuberculosis: A new chapter in the strategy of Revised National Tuberculosis Programme of India. National Journal of Community Medicine 2013;4 (3):541-4.

5. Sule AG, Odeigah LO, Alabi KM, Issa BA, Shittu RO, Joseph AI, et al. Quality of Life of Patients with Tuberculosis in a Nigerian Teaching Hospital. Turkish Journal of Family Medicine and Primary Care 2014;8 (2):39-47.

6. World Health Organization. Programme on mental health. Available from: http://www.who.int/mental_health/media/68.pdfhttp://ww w.who.int/ mental_health/media/68.pdf (Accessed on 13 December, 2017).

7. WHOQOL-BREF Introduction, Administration, Scoring and Generic Version of the Assessment. Field Trial Version December 1996. Programme on Mental Health. World Health Organization Geneva. Available at http://www.who.int/mental health/media/en/76.pdf (Accessed on 13 January 2016).

8. Sharma R, Yadav R, Sharma M, Saini V, Koushal V. Quality of Life of Multi Drug Resistant Tuberculosis Patients: a Study of North India. Acta Medica Iranica 2014;52:448-53.

9. Lawrence RC, Sathyamurthi K. Quality of Life of Multidrug Resistant Tuberculosis Patients in India. Golden Research Thoughts Journal 2015;5(2):1-8.

10. Ayub T, Nazir U, Sideeq K. Quality of Life of Multi Drug Resistant Tuberculosis Cases of Kashmir Valley. International Journal of Innovative Research in Medical Science 2017;2(8):1113-7.

11. Ahmad N, Javaid A, Sulaiman SAS, Basit A, Afridi AK, Jaber AAS, et al. Effects of Multidrug Resistant Tuberculosis Treatment on Patients' Health Related Quality of Life: Results from a Follow Up Study. PLOS
ONE 2016; 11(7): e0159560. doi:10.1371/journal.pone. 0159560

12. Atif M, Sulaiman SAS, Shafie AA, Asif M, Sarfraz MK, Low HC, et al. Impact of tuberculosis treatment on health-related quality of life of pulmonary tuberculosis patients: a follow- up study. Health and Quality of Life Outcomes 2014; 12:19. doi: 10. 1186/1477-7525-12-19.

13. Dhuria M, Sharma N, Ingle GK. Impact of Tuberculosis on the Quality of life.

Indian J Community Med 2008;33:58-9.

14. Aggarwal AN, Gupta D, Janmeja AK, Jindal SK. Assessment of health-related quality of life in patients with pulmonary tuberculosis under programme conditions. Int J Tuberc Lung Dis 2013;17 (7):947-53.

15. Rajkumar S, Vijayalakshmi S, Seetharaman N, Pajanivel R, Lokeshmaran A. Health-related quality of life among tuberculosis patients under Revised National Tuberculosis Control Programme in rural and urban Puducherry. Indian Journal of Tuberculosis 2017;64:14-9.

16. Dhuria M, Chopra KK, Sharma N, Rajpal S, Singh NP. Prognostic indicators in RNTCP and quality of life in tuberculosis patients. Indian J Prev Soc Med 2012;43:769. 